\title{
PSEUDOTUMOR RENAL TRAS EL USO DE MATERIALES HEMOSTÁTICOS EN LA NEFRECTOMÍA PARCIAL
}

\author{
E. MALlÉn MATEO, M.J. GIL SANZ, C. SANCHO SERRANO, D. PASCUAL REGUEIRO, \\ Á. GARCÍA DE JALÓN MARTÍNEZ, L.Á. RIOJA SANZ
}

Servicio de Urología. Hospital Universitario Miguel Servet. Zaragoza.

Actas Urol Esp. 28 (6): 455-457, 2004

\section{RESUMEN \\ PSEUDOTUMOR RENAL TRAS EL USO DE MATERIALES HEMOSTÁTICOS \\ EN LA NEFRECTOMÍA PARCIAL}

Después de una cirugía renal, en la que se usa materiales hemostáticos absorbibles, defectos residuales pueden persistir en los estudios radiológicos en los márgenes de la resección. Estos "pseudotumores" pueden ser confundidos con enfermedad recurrente o residual.

Presentamos un caso de pseudotumor renal tras nefrectomía parcial en un varón de 69 años, en el que se decidió actitud expectante, con resolución de la lesión a los 8 meses de la cirugía.

PALABRAS CLAVE: Neoplasias renales. Apósito absorbible. Nefrectomía.

\section{ABSTRACT \\ PSEUDOTUMOR RENAL AFTER PARTIAL NEPHRECTOMY WITH THE USE OF SURGICAL GELATIN SPONGE}

After renal parenchymal sparing surgery, with the use of surgical gelatin sponge, residual defects may persist on imaging studies at the sites of resection. These "pseudotumors" may lead to confusion as to whether a lesion was removed or has recurred. These lesions usually resolve within a year.

We report a case of pseudotumor renal parenchymal sparing surgery in a 69 year old man, with resolution of the lesion 8 months after surgery.

KEY WORDS: Kidney neoplasms. Absorbable esponge. Nephrectomy.

$\mathrm{E}$ n la reparación del parénquima renal tras una nefrectomía parcial es frecuente el uso de materiales hemostáticos, dato que debemos de tener en cuenta en el control y seguimiento tumoral de la patología renal, ya que defectos residuales pueden persistir en los estudios radiológicos en los márgenes de la resección, pudiendo ser confundidos con enfermedad recurrente o residual.

Tanto en la reparación quirúrgica renal como en el seguimiento tumoral han aportado gran experiencia patologías como la enfermedad de
Von Hippel-Lindau o el cáncer papilar hereditario, donde es importante la mayor preservación posible de la función renal $^{1}$.

\section{CASO CLÍNICO}

Paciente de 69 años de edad con antecedentes personales de linfoma no Hodgking de bajo grado (estadio IV óseo). Como antecedentes urológicos, sintomatología de TUI leve de larga evolución, sin presentar hematuria en ninguna ocasión.

Por su antecedente clínico era sometido a controles periódicos mediante TAC, diagnosticándose 
en 1998 de masa sólida de 38 mm en riñón derecho sugestiva de hipernefroma (Fig. 1). Por este motivo se sometió a nefrectomía parcial derecha. Con resultado anatomopatológico de hipernefroma de células claras, grado nuclear 2-3, con márgenes negativos (T1 NO MO).

En el acto quirúrgico, en la reparación del parénquima renal, se utilizó apósito hemostático absorbible de celulosa (Surgicel®). En el cuarto mes post-operatorio en un nuevo control con TAC, se observaron, por un lado, múltiples adenopatías retroperitoneales relacionadas con su linfoma y en el extremo inferior del riñón derecho un aumento de densidad del plano graso perirrenal y una formación heterogénea, que capta contraste, de $30 \times 21 \mathrm{~mm}$ en su cortical anterior, sugestivo de recidiva neoplásica (Fig. 2).

Se comenta el caso con el servicio de radiodiagnóstico contemplando la posibilidad de "pseudomasa" post-quirúrgica y con la conformidad del paciente se decide actitud expectante y nuevo control radiológico en 2 meses.

Tras este periodo en un nuevo scanner se observó disminución leve del tamaño y densidad de la lesión, compatibles con cambios post-quirúrgicos (Fig. 3).

Nuevamente a los 2 meses, se realiza TAC, persistiendo adenopatías propias de su enfermedad hematológica y normalidad en ambos riñones. Es decir, a los 8 meses de la cirugía, resolución de los cambios post-quirúrgicos (Fig. 4).

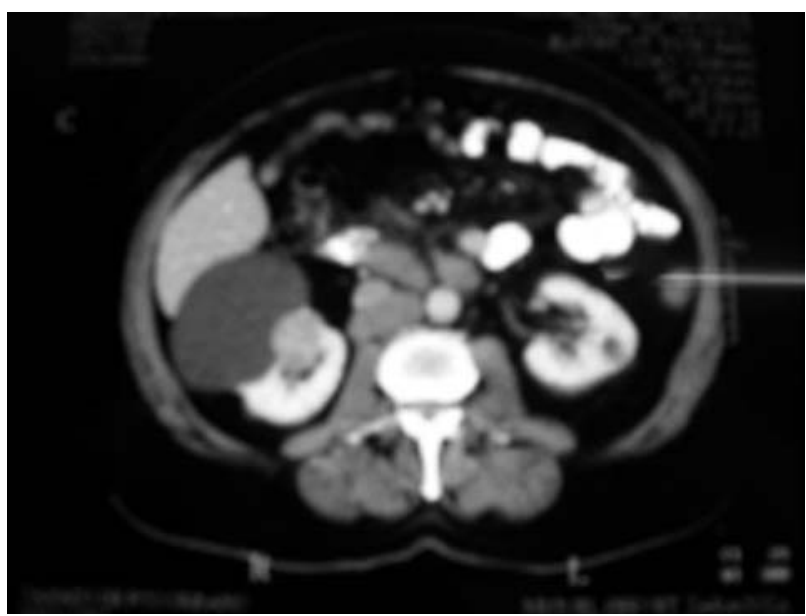

FIGURA 1. TAC abdominal: riñón derecho con quiste cortical simple adyacente al cual se identifica masa sólida de $38 \mathrm{~mm}$ sugestiva de hipernefroma.

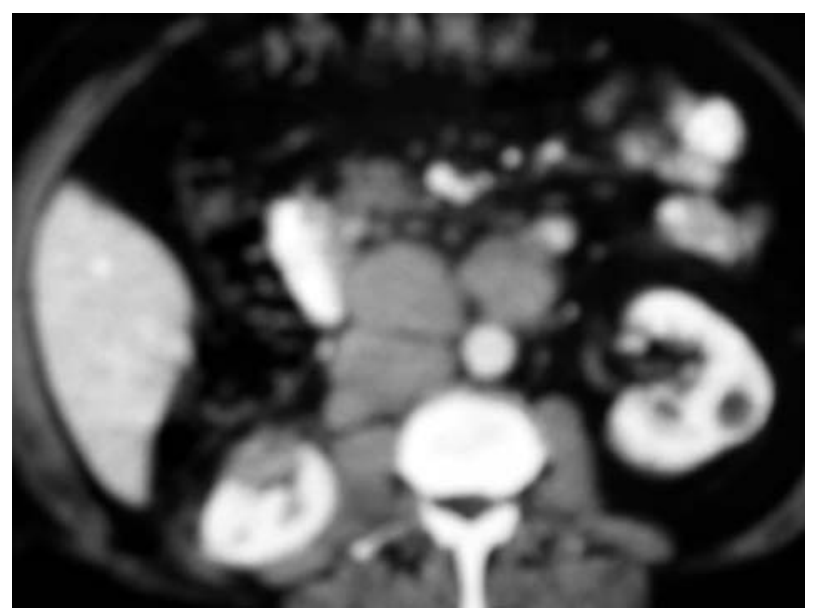

FIGURA 2. TAC abdominal: múltiples adenopatias retroperitoneales. Riñón derecho aumento de densidad del plano graso perirrenal y formación heterogénea de $30 x$ $21 \mathrm{~mm}$ en su cortical anterior que se extiende al plano perirrenal.



FIGURA 3. TAC abdominal: en riñón derecho imagen descrita en controles previos con disminución leve de tamaño, densidad y afectación perirrenal, pudiendo ser dichos cambios post-quirúrgicos.

Por su antecedente hematológico, el paciente siguió sometido a controles radiológicos mediante TAC sin observar lesión renal alguna.

\section{DISCUSIÓN}

En la revisión de la literatura Kshirsagar and cols. ${ }^{2}$ siguieron mediante controles radiológicos a 32 pacientes, con 46 reparaciones renales, durante 9 años. En todos estos pacientes se había utilizado esponja hemostática absorbible en el acto quirúrgico. 




FIGURA 4. TAC abdominal: riñón izquierdo con algún quiste cortical. Secuelas de nefrectomía polar inferior en riñón derecho. Sin imágenes sospechosas de recidiva.

De los 32 pacientes, 9 tuvieron un total de 13 pseudotumores en un primer estudio, teniendo en cuenta que la mayoría eran pacientes con enfermedad de Von Hippel-Lindau. Todos los pseudotumores en los controles radiológicos demostraron contornos regulares, realces tras el contraste intravenoso, simulando tumoración maligna renal. Se observaron 2 tipos de morfología en estos pseudotumores, quística por un lado y sólida en la mayoría de los casos.

Los controles con TAC demostraron en todos los casos la resolución de estas lesiones en una media de 13 meses.

La variabilidad en la resolución de estas lesiones no está del todo aclarada pero podría depender del grado de vascularización de las lesiones, la cantidad de apósito absorbible utilizado, la actividad del colágeno y de otros factores locales de la degradación.

Los apósitos absorbibles se vienen utilizando como agentes hemostáticos inertes, pero pueden simular en ocasiones tejidos de granulación, lo que explicaría la captación de contraste intravenoso en los estudios radiológicos y la consecuen- te simulación de tumoraciones. Hecho que debemos de tener en cuenta en el diagnóstico diferencial de tumoraciones que se presentan tras nefrectomía ${ }^{3}$.

\section{CONCLUCIONES}

Los pseudotumores renales son comúnmente vistos después de la cirugía reparadora del parénquima renal, en la que se ha utilizado materiales hemostáticos absorbibles, pudiendo ser confundidos con enfermedad recurrente o residual.

El realce del contraste observado en los estudios radiológicos parece ser debido a la granulación de los tejidos que envuelve el apósito hemostático. Aunque la media de resolución de estas lesiones es aproximadamente de 13 meses, en algún caso puede ser un periodo de tiempo mayor.

Es importante el seguimiento de estos pseudotumores mediante control radiológico para prevenir una posible confusión diagnóstica con enfermedad residual o recidiva tumoral, evitando así una innecesaria cirugía radical.

\section{REFERENCIAS}

1. WALTHER MM, CHOYKE PL, WEISS G, MANOLATOS C, LONG J, REITER R, ALEXANDER RB, LINEHAN WM.: Parenchymal sparing surgery in patients with hereditary renal cell cancer. $J$ Urol 1995; 153: 913.

2. KSHIRSAGAR AV, CHOIKE PL, LINEHAN WM, WALTHER MM.: Pseudotumors after renal parenchymal sparing surgery. J Urol 1998; 159 (4): 1148-1151.

3. SEICSHNAYDRE MA, SISMANIS A, HUGHES GB.: Update of reparative granuloma: surgery of the American Otological Society and the American Neurotology society. Amer J Otol 1994; 15: 155.

Dra. E. Mallén Mateo

C/ Isabel la Católica, 1-3

50009 Zaragoza

(Trabajo recibido el 19 septiembre de 2003) 